\title{
Prevalence and associated factors of Plasmodium falciparum and soil transmitted helminth infections among pregnant women in Osun state, Nigeria
}

\author{
Olusola Ojurongbe ${ }^{1}$, Patricia Nkem Okorie ${ }^{2}$, Rofiat Labake Opatokun ${ }^{1}$, Taiwo Adetola Ojurongbe ${ }^{3}$, \\ Victor Olatunji Mabayoje ${ }^{1}$, Olugbenga Adekunle Olowe ${ }^{1}$, Oluwaseyi Adegboyega Adeyeba ${ }^{1}$
}

1. Ladoke Akintola University of Technology, PMB 4400, Osogbo, Nigeria.

2. Institute for Advanced Medical Research and Training, College of Medicine, University of Ibadan.

3. Osun State University, Mathematical and Physical Sciences.

\begin{abstract}
Background: Plasmodium falciparum and soil transmitted helminth (STHs) infection are widespread in sub-Sahara Africa, where co-infection is also common. This study assessed the prevalence of these infections and their risk factors among pregnant women in Osogbo, Nigeria.

Methods: A total of 200 pregnant women attending the antenatal clinic were recruited. Plasmodium falciparum was detected using thick and thin film methods, while formol ether concentration method was used for STHs detection. A questionnaire was used to investigate the possible risk factors associated with acquisition of malaria and helminth infections.

Results: The prevalence of P. falciparum, STHs and their co-infection was $29.5 \%, 12 \%$ and $5 \%$ respectively. P. falciparum, STHs and $P$. falciparum + STHs co-infection was significantly higher in primigravidae (52.5\% vs $58.3 \%$ vs $80 \%)$ than in secongravidae $(18.6 \%$ vs $25.0 \%$ vs $20 \%)$ and multigravidae $(28.8 \%$ vs $16.7 \%$ vs $0 \%)(p=0.02)$. Prevalence associated factors identified for $P$. falciparum was age $(\mathrm{p}=0.0001)$ while gravidity $(\mathrm{p}=0.02)$ was identified for $P$. falciparum $+\mathrm{STHs}$ co-infection.

Conclusion: High prevalence of P. falciparum and helminth infections was observed among the pregnant women with primigravidae being the most susceptible to co-infection. There is an urgent need to implement an effective malaria and STHs preventive method for this high risk population.

Keywords: P.falciparum, STHs, Co-infection, pregnant women, Nigeria.

DOI: https://dx.doi.org/10.4314/ahs.v18i3.11

Cite as: Ojurongbe O, Okorie PN, Opatokun RL, Ojurongbe TA, Mabayoje VO, Olowe OA, Adeyeba OA. Prevalence and associated factors of plasmodium falciparum and soil transmitted helminth infections among pregnant women in Osun state, Nigeria. Afri Health Sci. 2018;18(3): 542-551. bttps://dx.doi.org/10.4314/abs.v18i3.11
\end{abstract}

\section{Introduction}

Malaria and soil transmitted helminths (STHs) infections are the most important parasitic infections in sub-Saharan Africa, where a significant proportion of the populations including pregnant women are exposed to these

\section{Corresponding author:}

Olusola Ojurongbe, Ladoke Akintola University of Technology, PMB 4400, Osogbo, Nigeria.

Email: oojurongbe@lautech.edu.ng infections. In Nigeria the coverage of antenatal care is put at $61 \%$ and maternal mortality rate is put at over 560/100,000 pregnant women annually ${ }^{1}$. Malaria caused by Plasmodium falciparum is one of the major problems encountered by these pregnant women living in malaria endemic areas of Nigeria ${ }^{2}$. Pregnant women have a higher density of parasitaemia and have more complications of P. falciparum infection than non-pregnant women ${ }^{3}$. Plasmodium falciparum infection contributes significantly to maternal anaemia, low birth weight of infants, intrauterine growth retardation, preterm deliveries and infant mortality in sub-Saharan Africa ${ }^{3,4,5}$. Similarly, STHs infections are widely distributed in tropical and sub-tropical areas 
of the developing countries ${ }^{6}$. STHs infections are associated with cognitive impairment and lowered educational achievement, anaemia, stunted growth, physical and mental development, malnutrition and responsible for about one million deaths per year ${ }^{7}$. Co-infection of P. falciparum and STHs is common given the spatial coincidence of risk between malaria and helminths infections among individual living in Africa ${ }^{8,6}$.

A major impact of malaria and STHs infections is anaemia which serves as a public health problem in the tropics ${ }^{9}$. Plasmodium falciparum has been shown to contribute significantly to anaemia in both pregnant women and young children using a number of mechanisms that includes haemolysis and phagocytosis ${ }^{3,10}$. Blood loss resulting from hookworm infection is considered as the main cause of anaemia ${ }^{11}$. Therefore the combination of $P$. falciparum and STHs (mostly hookworm infection) infection is considered as a strong indicator of moderate to serve anaemia ${ }^{12}$. Iron deficiency anaemia due to STHs infection depends on many factors, including the iron status of the individual and the bioavailability of iron in the diet. Most African women live on diets with poor bioavailable iron which results in low iron stores and could predispose helminth positive pregnant women to iron deficiency anae$\mathrm{mia}^{13}$. In addition, many other factors like environmental conditions, educational status, adherence to preventive measures could directly affect the prevalence of malaria and helminths in sub-Saharan Africa.

Few studies have reported the occurrence, interaction and risk factors of P. falciparum and helminths infection in pregnant women in Nigeria. Epidemiological surveillance and impact of both P. falciparum and STHs remain poorly defined among pregnant women in Nigeria. This study was therefore conducted to investigate the prevalence and risk factors of P. falciparum malaria and/or helminth co-infection in pregnant women in Osogbo, South Western, Nigeria.

\section{Methodology \\ Study area}

The study was carried out between October 2012 and May 2013 at the State General Hospital,Ikirun and Osogbo, Osun State, Nigeria. These communities are in urban areas in Osun State Nigeria. Osogbo is the state capital with a landed area of about 835 hectare and population projection of over 3 Million people as at 2006 population census. The climate in Osogbo is tropical with two seasons; October to February (dry season) and March to July rainy season. The average daily temperature is $32^{\circ} \mathrm{C}$ with a minimum temperature of $19^{\circ} \mathrm{C}$ and a maximum temperature of $35.9^{\circ} \mathrm{C}^{14}$. Malaria transmission is usually intense in the raining season in these two study areas.

\section{Study population and recruitment}

This was a cross-sectional study of pregnant women attending antenatal clinic. Inclusion criteria for participations were: pregnant women attending antenatal clinics, absence of general danger signs (for example vomiting, inability to sit or stand); absence of signs of severe and complicated falciparum malaria; absence of recent history of convulsion; absence of hyperpyrexia (i.e. axillary temperature $>39.5^{\circ} \mathrm{C}$ ) and informed consent of the participating women. The women were adequately informed on the benefit and risks of the study and their consent was sought verbally. Only consented women were recruited into the study. Ethical approval was obtained from Ethical committee of the State Hospital at the Hospital Management Board, Osogbo. After verbal consent, questionnaire were administered to collect information on age, parity, gestational age, toilet facilities, malaria prevention methods and history of drugs taken. The number of pregnant women included in this study was determined using the formula.

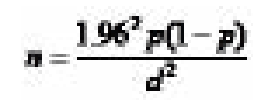

The prevalence of $P$. falciparum was estimated as $35 \%$ based on the averge value of a wide range of publications in this area. The marginal error was considered as $5 \%$ using 95\% confidence level (standard value 1.96); the minimum sample size was determined to be approximately 188 and subsequently 200 was collected. This research was reviewed and approved by the Ethical Review Committee of the Osun State Ministry of Health, Osogbo.

\section{Sample collection and analysis}

Blood was collected from the thumb with a sterile lancet onto two seperate slides after cleaning the thumb with methylated spirit. The slides were used for the examination and estimation of malaria parasite from thick and thin film preparation. Blood was also collected into heparinised capillary tube for PCV estimation. A wide mouth 
clean specimen bottle with tight screw cover was individual provided for each participant for collection of stool sample in the morning of the day of their antenatal clinic visit. The sample was collected early in the morning and processed less than 12 hours when it was passed. The stool samples were visualized macroscopically. Direct saline and formol-ether concentration method of stool samples were prepared and microscopically examined using $10 \times$ and $40 \times$ objectives $^{15}$.

\section{Data analysis}

Data analysis was performed using SPSS version 16.0. Chi- square tests and descriptive statistics were used to describe the differences in socio-demographic charactersitics. P-value $\leq 0.05$ was considered significant. Point estimation of prevalence of malaria and STHs infection was calculated based on the blood and stool sample results. The comparison of prevalence of P. falciparum, STHs and
P. falciparum + STHs co-infection between malaria and STHs was performed using chi square test. Odds ratios (OR) with a $95 \%$ confidence interval were computed to compare the strength of association.

\section{Results}

General characteristics of the study population

A total of 200 pregnant women with a mean age of 26.5 years (range:15-40) were enrolled in this study (Table 1). The mean gestational age of the pregnant women at enrolment was 17.4 weeks (range: 8-36 weeks). The mean packed cell volume (PCV) was 35.94 6 6.50. The overallprevalence of $P$. falciparum and STHs was 29.5\% (59/200) and $12 \%(24 / 200)$ respectively (Table 1$)$. Out of the 59 malaria positive pregnant women, $24.5 \%(\mathrm{n}=49)$ were positive for $P$. falciparum only, $6.5 \%(\mathrm{n}=13)$ were positive for STHs only while $5.0 \%(n=10)$ were co-infected with P. falciparum and STHs. Two (1\%) of the STHs infected women had co-infection of hookworm + A. lumbricoides

Table 1 Participants characteristics and prevalence of malaria and helminthic infection among pregnant and non- pregnant women

\begin{tabular}{ll}
\hline Characteristics & Pregnant $(N=200)$
\end{tabular}

\begin{tabular}{ll}
\hline Mean Age (yrs) \pm SD & $26.5 \pm 5.3$ \\
Mean Gestational Age (weeks) \pm SD & $17.4 \pm 5.8$ \\
Mean packed cell volume \pm SD & $35.9 \pm 6.5$ \\
Mean weight \pm SD & $58.8 \pm 8.2$ \\
Prevalence of $P$. falciparum & $29.5 \%(59 / 200)$ \\
Prevalence of Intestinal helminth & $12.0 \%(24 / 200)$ \\
i. $\quad$ Ascaris lumbricoides & $10.0 \%(20 / 200)$ \\
ii. Hookworm $\quad$ Strongyloides stecoralis & $2.0 \%(4 / 200)$ \\
iii. $\quad 1.0 \%(2 / 200)$ \\
Malaria/helminth co-infection & $5.0 \%(10 / 200)$ \\
Hookworm/Ascaris co-infection & $1.0 \%(2 / 200)$ \\
Primigravida vs Multigravida & 78 vs 122 \\
\hline
\end{tabular}


Prevalence of $P$. falciparum and STHs

The prevalence of $P$. falciparum, STHs and $P$. falciparum + STHs co-infection with respect to age, gravidity and gestational age is shown in Table 2 . The highest prevalence of P. falciparum infection was recorded in the age group $>30$ years $(49.2 \%)$ followed by age group $25-$ 29 years $(30.5 \%)$ and the least in age group $<20(5.1 \%)$ and the difference was statistically significant $(\mathrm{p}=0.001)$. Prevalence of P.falciparum and STHs infection was high- er among primigraviadae, but the difference was not statistically significant. For P. falciparum + STHs co-infection the primigravidae $(80 \%)$ had the highest prevalence compared to secongravidae $(20 \%)$ and multigravidae $(0 \%)$ and the difference was statistically significant $(p=0.02)$. Those in the second trimester of pregnancy had the highest prevalence of falciparum (57.6\%), STHs (70.8) and P.falciparum + STHs co-infection $(70 \%)$ but the difference was not statistically significant.

Table 2: Prevalence of Malaria and intestinal helminth infection among pregnant by age, parity, gestational age and $\mathrm{PCV}$

\begin{tabular}{|c|c|c|c|c|c|c|c|}
\hline Characteristics & $\begin{array}{l}\text { No. } \\
\text { Examined }\end{array}$ & $\begin{array}{l}\text { P. } \\
\text { falciparum } \\
+ \text { ve (\%) }\end{array}$ & p-value & $\begin{array}{l}\text { Helminth } \\
\text { +ve (\%) }\end{array}$ & p-value & $\begin{array}{l}\text { P.falciparum+ } \\
\text { Helminth (\%) }\end{array}$ & p-value \\
\hline \multicolumn{8}{|l|}{ Age group (yrs) } \\
\hline$<20$ & 12 & $3(5.1)$ & & 0 & & 0 & \\
\hline $20-24$ & 57 & $9(15.3)$ & 0.001* & $10(41.7)$ & 0.08 & $2(20.0)$ & 0.39 \\
\hline 25-29 & 71 & $18(30.5)$ & & $11(45.8)$ & & $6(60.0)$ & \\
\hline$\geq \mathbf{3 0}$ & 60 & $29(49.2)$ & & $3(12.5)$ & & $2(20.0)$ & \\
\hline \multicolumn{8}{|l|}{ Gravidity } \\
\hline Primigravidae & 78 & $31(52.5)$ & & $14(58.3)$ & & $8(80.0)$ & \\
\hline Secongravidae & 60 & $11(18.6)$ & 0.22 & $6(25.0)$ & 0.09 & $2(20.0)$ & $0.02 *$ \\
\hline $\begin{array}{l}\text { Multigravidae } \\
\text { Gestational age }\end{array}$ & 62 & $17(28.8)$ & & $4(16.7)$ & & $0(0.0)$ & \\
\hline First trimester & 63 & $20(33.9)$ & 0.23 & $4(16.7)$ & & $3(30.0)$ & 0.71 \\
\hline $\begin{array}{l}\text { Second } \\
\text { trimester }\end{array}$ & 120 & $34(57.6)$ & & $17(70.8)$ & 0.38 & $7(70.0)$ & \\
\hline $\begin{array}{l}\text { Third } \\
\text { trimester } \\
\text { PCV }\end{array}$ & 17 & $5(8.5)$ & & $3(12.5)$ & & 0 & \\
\hline$>30 \%$ & 156 & $49(83.1)$ & & $17(70.8)$ & & $7(70.0)$ & \\
\hline$\leq 30 \%$ & 44 & $10(17.0)$ & 0.35 & $7(29.2)$ & 0.367 & $3(30.0)$ & 0.53 \\
\hline
\end{tabular}

\footnotetext{
$*$ Values are statistically significant $(\mathrm{p} \leq 0.05)$
} 
Association between P. falciparum and intestinal helminth

The association between $P$. falciparum and STHs infection among the pregnant women is shown in Table 3. Out of the 59 pregnant women that were positive for malaria, $10(16.9 \%)$ were co-infected with STHs and the difference was not statistically significant $(p=0.23)$. In the final model, children infected with helminths in this study are almost twice as likely to have P. falciparum infection than those without helminth infection (OR=1.85 (95\% confidence interval CI: 0.77-4.45). An increase odds of $P$. falciparum was also observed among children infected with A. lumbricoides when compared to those not infected (OR $=2.13$; CI: $0.83-5.44)$. Although a similar observation to those of $A$. lumbricoides was observed for hookworm and $S$. stercoralis, only one observation was recorded in both cases which makes the analysis not extremely reliable ( $\mathrm{Ta}-$ ble 3).

\section{Table 3: Relationship between malaria and intestinal helminth infection among pregnant women}

\begin{tabular}{|c|c|c|c|c|}
\hline \multirow[t]{2}{*}{ Helminth infection } & \multicolumn{2}{|c|}{ P. falciparum infection (\%) } & \multirow{2}{*}{$\begin{array}{l}\text { Odds Ratio } \\
(95 \% \mathrm{Cl})\end{array}$} & \multirow{2}{*}{$\begin{array}{l}\text { p- } \\
\text { value }\end{array}$} \\
\hline & $\begin{array}{l}\text { Positive } \\
\text { n=59 }(\%)\end{array}$ & $\begin{array}{l}\text { Negative } n=141 \\
(\%)\end{array}$ & & \\
\hline $\begin{array}{l}\text { Any intestinal helminth } \\
\text { infection }\end{array}$ & $10(16.9)$ & $14(9.9)$ & $1.85(0.77-4.45)$ & 0.23 \\
\hline Ascaris lumbricoides & $9(15.3)$ & $11(7.8)$ & $\begin{array}{l}2.13(0.83- \\
5.44)\end{array}$ & 0.12 \\
\hline Hookworm & $1(1.7)$ & $3(2.1)$ & $0.79(0.08-7.78)$ & 1.00 \\
\hline Strongyloides & $1(1.7)$ & $1(0.7)$ & $\begin{array}{l}2.41(0.15- \\
39.25)\end{array}$ & 0.50 \\
\hline $\begin{array}{l}\text { A. lumbricoides / Hookworm co- } \\
\text { infection }\end{array}$ & $1(1.7)$ & $1(0.7)$ & $2.41(0.15-39.25$ & 0.50 \\
\hline
\end{tabular}

Influence of demographic and attitudinal practice on P.falciparum and helminth infection

Table 4 shows the influence of demographic characteristics and attitudinal practice on P.falciparum and STHs infection in the study population. Age was significantly associated with P.falciparum infection $(\mathrm{P}=0.0001)$ among pregnant women in the study area. Education, employment status, toilet facility type, gravidity and gestational age were not significantly associated with $P$. falciparum infection. Age, education, employment status, toilet facility type and gestational age were not significantly associated with $P$. falciparum infection. None of the factors was found to be significantly associated with STHs infection. The highest prevalence of STHs was among pregnant women aged $25-29$ years $(45.8 \% ; 11 / 24)$, unemployed $(41.7 \% ; 10 / 24)$ and self-employed $(41.7 \% ; 10 / 24)$, primigravidae $(58.3 \%$; 14$)$, those who used pit latrines $(58.3 \%$; $14 / 24)$ and those who were in the second trimester of pregnancy $(70.8 \% ; 17 / 24)$. Of the 24 pregnant women positive for helminths, $7(29.2 \%)$ were anaemic while $17 \%(10 / 59)$ of the malaria positive pregnant women were also anaemic with PCV $\leq 30 \%$ (Table 3 ). The highest prevalence of malaria was found among women aged $>30$ yrs $(49.2 \%)$, unemployed $(47.5 \%)$, and those that used pit latrines (49.2\%). Three of the 10 pregnant women with $P$. falciparum helminth co-infection were anaemic. Amongst the 10 pregnant women co infected with $P$. falciparum and STHs, the highest prevalence was observed 
among pregnant women aged 25-29 years (60\%), unemployed $(50 \%)$, those who used pit latrines $(50 \%)$, those in the second trimester of pregnancy $(70 \%)$ and those who had not taken any sulfadoxine-pyrimethamine (SP) for malaria prevention $(70 \%)$ but the differences were not statistically significant (table 3). Prevalence of P. falciparum was also higher among primigraviadae $(52.5 \%)$, women in the second trimester of pregnancy $(57.6 \%)$ and women who had not received any SP for malaria prevention $(55.9 \%)$ (Table 4).

\section{Table 4: Risk factors associated with malaria and helminths infection among pregnant women}

\begin{tabular}{|c|c|c|c|c|c|c|c|}
\hline Characteristics & $\begin{array}{l}\text { No. } \\
\text { Examined } \\
200 \\
\end{array}$ & $\begin{array}{ll} & \text { Malaria } \\
n- & n=59(\%)\end{array}$ & $\begin{array}{l}p- \\
\text { valuc }\end{array}$ & $\begin{array}{l}\text { Helminth } \\
\mathrm{n}=24 \\
(\%)\end{array}$ & $\begin{array}{l}p- \\
\text { value }\end{array}$ & $\begin{array}{l}\text { Malaria/ } \\
\text { Helminth } \\
\text { n=10 }(\%)\end{array}$ & $\begin{array}{l}p- \\
\text { value }\end{array}$ \\
\hline \multicolumn{8}{|l|}{ Education } \\
\hline None & 23 & $5(8.5)$ & & $2(8.3)$ & & 0 & \\
\hline Primary & 37 & $14(23.7)$ & \multirow{3}{*}{0.18} & $4(16.7)$ & \multirow{3}{*}{0.823} & $3(30.0)$ & \multirow{3}{*}{0.71} \\
\hline Junior Sec & 65 & $14(23.7)$ & & $7(29.2)$ & & $2(20.0)$ & \\
\hline$\geq$ Senior Sec & 75 & $26(44.1)$ & & $11(45.8)$ & & $5(50.0)$ & \\
\hline \multicolumn{8}{|c|}{ Employment Status } \\
\hline Unemployed & 76 & $28(47.5)$ & \multirow{4}{*}{0.20} & $10(41.7)$ & \multirow{4}{*}{0.79} & $5(50.0)$ & \multirow{4}{*}{0.58} \\
\hline Employed & 44 & $11(11.6)$ & & $4(16.7)$ & & $1(10.0)$ & \\
\hline Self-employed & 80 & $20(33.9)$ & & $10(41.7)$ & & $4(40.0)$ & \\
\hline \multicolumn{5}{|l|}{ Toilet facilities } & & & \\
\hline Pit latrine & 96 & $29(49.2)$ & \multirow{3}{*}{0.95} & $14(58.3)$ & \multirow{3}{*}{0.12} & $5(50.0)$ & \multirow{3}{*}{0.43} \\
\hline Water closet & 78 & $23(39.0)$ & & $10(41.7)$ & & $5(50.0)$ & \\
\hline None & 26 & $7(11.9)$ & & ) & & 0 & \\
\hline \multicolumn{8}{|l|}{ SP Usage } \\
\hline No & 106 & $33(55.9)$ & & $16(66.7)$ & & $7(70.0)$ & \\
\hline Yes & 94 & $26(44.1)$ & 0.64 & $8(33.3)$ & 0.15 & $3(30.0)$ & 0.267 \\
\hline \multicolumn{8}{|c|}{ Use of prevention methods } \\
\hline No & 38 & $9(15.3)$ & & $4(16.7)$ & & $3(30.0)$ & \\
\hline Yes & 162 & $50(84.7)$ & 0.43 & $20(83.3)$ & 0.76 & $7(70.0)$ & 0.36 \\
\hline
\end{tabular}

\section{Discussion}

This study presents data on the prevalence of P. falciparum and STHs co-infection and some possible associated risk factors in pregnant women in South Western, Nigeria. $P$. falciparum is a major cause of mortality in pregnant women and their foetus and it is endemic in many parts of the world where its co-occurrence with STHs has been reported ${ }^{16}$. This study observed that malaria is still highly prevalent among pregnant women in Nigeria. The 29.5\% prevalence of $P$. falciparum recorded in this study was similar to the prevalence of $21.9 \%$ reported in Ilorin Nigeria, $21.9 \%$ in Cameroon ${ }^{17}$, and $36.3 \%$ in $\mathrm{Ghana}^{18}$. However the prevalence was lower than the reports from some other parts of Nigeria (Kebbi $(41.6 \%)^{19}$, Ethiopia $(11.6 \%)^{20}$ and Libreville (Gabon) (57\%) ${ }^{21}$. Also, a study in Ango- la and Sudan recorded a prevalence of $8.6 \%$ and $13.7 \%$ respectively among pregnant women ${ }^{22,23}$. The differences in the prevalence of $P$. falciparum in pregnancy may be attributed to various reasons like sample size, abundance of vector but also primarily linked availability of effective control measures in the endemic areas.

Although WHO recommends two doses of sulfadoxine-pyrimethamine (IPTp-SP) for malaria prophylaxis in pregnancy ${ }^{24}, 53 \%$ of the women in this study did not recieved any SP prescription during Ante-Natal Care (ANC) and only $47.0 \%$ recieved one or two doses. Use of IPTp has been shown to decrease Plasmodium parasitemia ${ }^{25}$ but unfortunately the implementation of this recommendation has been sub-optimal in many endemic countries as 
observed in our study. Improving the coverage of pregnant women receiving IPTp in malaria endemic region, like in Nigeria is essential in other to reduce the mortality associated with malaria in pregnenacy.

An overall prevalence of $12.0 \%$ was observed for STHs infections amongst pregnant women in this study. This shows the susceptibility of the pregnancy state to infection which could be due to impaired immunity ${ }^{25}$. The prevalence observed in our study is lower compared to what was reported in Ghana $(25.7 \%)^{18}$, Ethiopia $(41 \%)^{20}$ and Kenya $(13.8 \%)^{26}$. The relatively low prevelence of STHs in this study could be an indication of improved sanitation and proper sewage disposal and improved toilet facilities as shown by the fact that $39 \%$ of the participant had improved toilet facilities. The prevalence of $A$. lumbricoides $(15.3 \%)$ was higher than those of other helminths, an observation that has been made in other studies in North Central and South South region of Nigeria $(19.1 \%)^{27}$. However, the prevalence of $A$. lumbricoides recorded here was higher than $5.0 \%$ recorded in South Eastern Nigeria ${ }^{28}$ and Kenya ${ }^{26}$.

Only, $5 \%$ of the participants in this study were co-infected with P. falciparum and STHs of the women who had malaria while $12 \%$ had some type of worm infection. Awareness of the importance of co-infection is increasing and suggestions have been made that helminths infection may influence susceptibility to other infections including malaria (Nacher 2001; Bentwich, 2000). This association may vary by geographical region, the local species and the risk factors for the parasites being studied $^{29}$. In this study, although no significant association was observed in the interaction between helminth and malaria, the odds revealed that pregnant women infected with helminths, more precisely $A$. lumbricoides were almost two times as likely to have $P$. falciparum infection compared to those without $A$. lumbricoides infection. This is similar to our previous observation in studies conducted among school children in different locations in Nigeria ${ }^{6,30}$. Also, similar association was previously observed among cohort of pregnant women in Ghana ${ }^{18}$. Although the main reason for this observation is yet to be elucidated, the general belief is that helminths drive the type 2 (Th2) immune response which down-regulates the Th1 anti-malarial immune response, resulting in increased risk of malaria infection. This explanation may not hold true in all circumstances as other authors have conflicting reports on how helminths regulate P. falciparum infection. More studies are therefore needed to expound on these conflicting observations.

Although, the prevalence of P. falciparum, STHs and co-infection was higher among the primigravidae compared to secondigravida and multigravida, no significant association was observed between primiparity and P. falciparum infection. However, primiparity was significantly associated with P. falciparum and STHs coinfection. Primiparity has been identified as a risk factor for P. falciparum infection during pregnancy ${ }^{3,21,25,29}$.

Majority of the pregnant women were not anaemic and so had a PCV value of $30 \%$ or more. A study in Ethiopia recorded anaemia prevalence of $53.9 \%$ among pregnant women $^{31}$. Anaemia (PCV $\leq 30 \%$ ) was not associated with $P$. falciparum infection, STHs infection and P. falciparum + STHs co-infection among the pregnant women studied. Lack of association between hookworm and anaemia has been reported in Brazil ${ }^{11}$. Hookworm may cause anaemia particularly in pregnant women ${ }^{32}$ and hemoglobin levels have been found to be lowest in pregnant women who had helminth or malaria infections ${ }^{33}$.

Age was identified as a risk factor for malaria in pregnancy while gravidity was a risk factor for $P$. falciparum + STHs co-infection. Previous studies have identified the risk factors for malaria in pregnancy as age and primigravidae ${ }^{10,21,25}$. However, a lack of association between age or parity and malaria has been reported in Sudan ${ }^{22}$. No risk factor was identified for helminth infection in this study. Any risk factors (if present) in this study might not have been detected in this study given the low number of women who were infected with helminths (especially with hookworm). Again the use of one stool sample from each woman is a limiting factor as the proportion of women with low-intensity infection could have been mis-classifed as uninfected since multiple samples are required for accurate detection ${ }^{34}$. Future study with larger sample size is therefore recommended to help further investigate the impact anemia and other risk factor in pregnant women.

The risk factors for helminth infections depend on the route of transmission and life cycle of the helminth, and are related to the state of hygiene, sanitation and environmental conditions (temperature and humidity) ${ }^{16,35}$. It is also worth noting that pregnant women in the rural 
communities who are the most vulnerable to malaria and helminth infection do not attend antenatal clinics. The implication of this is that higher prevalence of malaria, helminth and malaria helmith coinfection could be recorded in a rural community based study. Also other studies have shown other risk factors associated with STHs infection include the absence of garbage bin in the household and age of the mother at the time of marriage, house floor type or handwash $33,36,37$. However, data for these factors were not included in the study and may have an effect which was not observed. Poor education and unemployment have also been identified as risk factors for both helminth and P. falciparum infections ${ }^{33}$.

\section{Conclusion}

The results suggest that $P$. falciparum and STHs infection and their co-infection could constitute a serious problem among women attending antenatal clinic (ANC) with primigravida being more parasitized than the multigravida. More effort should be placed on the control and prevention of malaria and intestinal helminths among pregnant women in endemic areas in other to reduce the associated risks and burden.

\section{Acknowledgement}

The authors are grateful to all the participants and nurses of the hospitals

\section{Disclosures and ethics}

The authors have no competing interests in the manuscript. The authors also confirmed that this article is unique and not under consideration or published in any other journal.

\section{References}

1. Fagbamigbe AF, Idemudia ES. Barriers to antenatal care use in Nigeria: evidences from non-users and implications for maternal health programming. BMC Pregnancy Childbirth. 2015;15:95. doi:10.1186/s12884-015-0527-y.

2. Ojurongbe O, Tijani BD, Fawole AA, Adeyeba OA, Kun JF. Prevalence of Dihydrofolate reductase gene mutations in Plasmodium falciparum isolate from pregnant women in Nigeria. Infect Dis Rep. 2011;3. doi:10.4081/ idr.2011.e16.

3. Shulman C, Dorman E. Reducing childhood mortality in poor countries: Importance and prevention of malaria in pregnancy. Trans R Soc Trop Med Hyg. 2003;97:30-5.

4. Steketee R, Nahlen B, Parise M, Nenendez C. The burden of malaria in pregnancy in malaia endemic areas. $A m$ J Trop Med Hyg. 2001;64:28-35. PubMed.

5. Yatich NJ, Jolly PE, Funkhouser E, Agbenyega T, Rayner JC, Ehiri JE, et al. The effect of malaria and intestinal helminth co-infection on birth outcomes in Kumasi, Ghana. Am J Trop Med Hyg. 2010;82:28- 34. PubMed. doi:10.4269/ajtmh.2010.09-0165.

6. Ojurongbe O, Adegbayi AM, Bolaji OS, Akindele AA, Adefioye OA, Adeyeba OA. Asymptomatic falciparum malaria and intestinal helminths co-infection among school children in Osogbo, Nigeria. J Res Med Sci Off I Isfahan Univ Med Sci. 2011;16:680-6.

7. Pullan RL, Smith JL, Jasrasaria R, Brooker SJ. Global numbers of infection and disease burden of soil transmitted helminth infections in 2010. Parasit Vectors. 2014;7:37. PubMed. doi:10.1186/1756-3305-7-37.

8. Brooker S, Clements A, Hotez P, Hay S, Tatem A, Bundy $\mathrm{D}$, et al. The co-distribution of Plasmodium falciparum and hookworm among African school children. Malar J. 2006;5:99. PubMed. doi:10.1186/1475-2875-5-99.

9. Brooker S, Alexander N, Geiger S. Contrasting patterns in the small-scale heterogeneity of human helminth infections in urban and rural environments in Brazil. Int J Parasitol. 2006;36:1143- 51. PubMed.

10. Tako E a., Zhou A, Lohoue J, Leke R, Taylor DW, Leke RFG. Risk factors for placental malaria and its effect on pregnancy outcome in Yaounde, Cameroon. Am J Trop Med Hyg. 2005;72:236- 42. PubMed.

11. Brooker S, Jardim-Botelho A, Quinnell RJ, Geiger SM, Caldas IR, Fleming F, et al. Age-related changes in hookworm infection, anaemia and iron deficiency in an area of high Necator americanus hookworm transmission in South-eastern Brazil. Trans R Soc Trop Med Hyg. 2007;101:146-54. doi:10.1016/j.trstmh.2006.05.012.

12. Dreyfuss ML, Stoltzfus RJ, Shrestha JB,Pradhan EK, LeClerq SC, Khatry SK, et al. Hookworms, malaria and vitamin A deficiency contribute to anemia and iron deficiency among pregnant women in the plains of Nepal. $J$ Nutr. 2000;130:2527-36. PubMed. doi:2527-2536.

13. Binetou $\mathrm{C}$, Robert $\mathrm{T}$. Iron deficiency is a major risk factor for anemia among pregnant women in Senegal. Afr J Health Sci. 2011;18:96- 104. PubMed. 
14. Norwegian Meteorologisk Institutt. Weather statistics for Osun State. Yr.no 2017. https://www.yr.no/place/ Nigeria/Osun/Osun_State (accessed August 6, 2017).

15. Cheesbrough M. District Laboratory Practice in Tropical Countries Part 1. United Kingdom: Cambridge University Press, Cambridge; 2009.

16. Brooker S, Akhwale W, Pullan R, Street K, Wce L, Estambale B. Epidemiology of Plasmodium-helminth co-infection in Africa: populations at risk, potential impact on anemia and prospects for combining control. Am J Trop Med Hyg. 2009;77:88-98. PubMed.

17. Leke RFG, Djokam RR, Mbu R, Leke RJ, Fogako J, Megnekou R, et al. Detection of the Plasmodium falciparum antigen histidine-rich protein 2 in blood of pregnant women: Implications for diagnosing placental malaria. $J$ Clin Microbiol. 1999;37:2992- 6. PubMed.

18. Yatich NJ, Yi J, Agbenyega T, Turpin A, Rayner JC, Stiles JK, et al. Malaria and intestinal helminth co-infection among pregnant women in Ghana: Prevalence and risk factors. Am J Trop Med Hyg. 2009;80:896- 901. PubMed.

19. Fana SA, Bunza MDA, Anka SA, Imam AU, Nataala SU. Prevalence and risk factors associated with malaria infection among pregnant women in a semi-urban community of North-Western Nigeria. Infect Dis Poverty. 2015;4:24. PubMed. doi:10.1186/s40249-015-0054-0.

20. Getachew M, Tafess K, Zeynudin A, Yewhalaw D. Prevalence soil transmitted helminthiasis and malaria co-infection among pregnant women and risk factors in Gilgel Gibe Dam area, SouthWest Ethiopia. BMC Res Notes. 2013;6:263. PubMed. doi:10.1186/1756-0500-6263.

21. Bouyou-Akotet MK, Ionete-Collard DE, Mabika-Manfoumbi M, Kendjo E, Matsiegui P-B, Mavoungou E, et al. Prevalence of Plasmodium falciparum infection in pregnant women in Gabon. Malar J. 2003;2:18. PubMed. doi:10.1186/1475-2875-2-18.

22. Adam I, Khamis AH, Elbashir MI. Prevalence and risk factors for Plasmodium falciparum malaria in pregnant women of eastern Sudan. Malar J. 2005;4:18. PubMed. doi:10.1186/1475-2875-4-18.

23. Valente B, Campos P, do Rosario V, Varandas L, Silveira H. Prevalence and risk factors of Plasmodium falciparum infections in pregnant women of Luanda, Angola. Trop Med Int Health. 2011;16:1206- 14. PubMed. doi:10.1111/j.1365-3156.2011.02830.x.
24. World Health Organization. WHO policy brief for the implementation of intermittent preventive treatment of malaria in pregnancy. 2014.

25. Rogerson SJ, Mwapasa V, Meshnick SR. Malaria in pregnancy: Linking immunity and pathogenesis to prevention. Am J Trop Med Hyg. 2007;77:14 - PubMed. 22. doi:77/6_Suppl/14 pii.

26. Wekesa AW, Mulambalah CS, Muleke CI, Odhiambo R. Intestinal helminth infections in pregnant women attending antenatal clinic at Kitale district hospital, Kenya. J Parasitol Res. 2014;2014.

27. Egwunyenga a. O, Ajayi J a., Nmorsi OPG, Duhlinska-Popova DD. Plasmoduim/intestinal helminth co-infections among pregnant Nigerian women. Mem Inst Oswaldo Cruq. 2001;96:1055-9. doi:10.1590/S007402762001000800005.

28. Obiezue NR, Okoye IC, Ivoke N, Okorie JN. Gastrointestinal Helminth Infection in Pregnancy: Disease Inci- dence and Hematological Alterations. Iran J Public Health. 2013;42:497-503.

29. Adegnika A, Ramharter M, Agnandji ST, Ngoa UA, Issifou S. Epidemiology of parasitic co-infections during pregnancy in Lambarene, Gabon. Trop Med Int Health. 2010;15:1204-9. PubMed. doi:10.1111/j.13653156.2010.02598.x.

30. Adedoja A, Tijani BD, Akanbi AA II, Ojurongbe TA, Adeyeba OA, Ojurongbe O. Co-endemicity of Plasmodium falciparum and Intestinal Helminths Infection in School Age Children in Rural Communities of Kwara State Nigeria. PLoS Negl Trop Dis. 2015;9:e0003940. doi:10.1371/ journal.pntd.0003940.

31. Getachew M, Yewhalaw D, Tafess K, Getachew Y, Zeynudin A. Anaemia and associated risk factors among pregnant women in Gilgel Gibe dam area, SouthWest Ethiopia. Parasit Vectors. 2012;5:296. PubMed. doi:10.1186/1756-3305-5-296.

32. Brooker S, Hotez PJ, Bundy D a P. Hookworm-related anaemia among pregnant women: A systematic review. PLoS Negl Trop Dis. 2008;2. doi:10.1371/journal. pntd.0000291.

33. Ivan E, Crowther NJ, Mutimura E, Osuwat LO, Janssen S, Grobusch MP. Helminthic infections rates and malaria in HIV-infected pregnant women on anti-retroviral therapy in Rwanda. PLoS Negl Trop Dis. 2013;7:1- 9. PubMed. doi:10.1371/journal.pntd.0002380.

34. Hillier SD, Booth M, Muhangi L, Nkurunziza P, Kh- 
ihembo M, Kakande M, et al. Plasmodium falciparum and helminth coinfection in a semi urban population of pregnant women in Uganda. J Infect Dis. 2008;198:920- 7. PubMed. doi:10.1086/591183.

35. Woodburn PW, Muhangi L, Hillier S, Ndibazza J, Namujju PB, Kizza M, et al. Risk factors for helminth, malaria, andHIV infection in pregnancy in Entebbe, Uganda. PLoS Negl Trop Dis. 2009;3. doi:10.1371/journal. pntd.0000473.
36. Curtale F, Pezzotti P, Saad YS, Aloi A. An analysis of individual, household, and environmental risk factors for intestinal helminth infection among children in Qena Governorate , Upper Egypt. J Trop Paediatr. 1999;45:147. PubMed.

37. Pullan RL, Bethony JM, Geiger SM, Cundill B, Correa-Oliveira R, Quinnell RJ, et al. Human helminth co-infection: Analysis of spatial patterns and risk factors in a Brazilian community. PLoS Negl Trop Dis. 2008;2. doi:10.1371/journal.pntd.0000352. 